\title{
Surgical indication analysis according to bony defect size in pediatric orbital wall fractures
}

\author{
Seung Hyun Kim, \\ Jun Ho Choi, \\ Jae Ha Hwang, \\ Kwang Seog Kim, \\ Sam Yong Lee
}

Department of Plastic and

Reconstructive Surgery, Chonnam

National University Medical School,

Gwangju, Korea

\begin{abstract}
Background: Orbital fractures are the most common pediatric facial fractures. Treatment is conservative due to the anatomical differences that make children more resilient to severe displacement or orbital volume change than adults. Although rarely, extensive fractures may result in enophthalmos, causing cosmetic problems. We aimed to establish criteria for extensive fractures that may result in enophthalmos.

Methods: We retrospectively reviewed the charts of patients aged $0-15$ years diagnosed with orbital fractures in our hospital from January 2010 to February 2019. Computed tomography images were used to classify the fractures into linear, trapdoor, and open-door types, and to estimate the defect size. Data on enophthalmos severity (Hertel exophthalmometry results) and fracture pattern and size at the time of injury were obtained from patients who did not undergo surgery during the follow-up and were used to identify the surgical indications for pediatric orbital fractures.

Results: A total of 305 pediatric patients with pure orbital fractures were included-257 males (84.3\%), 48 females (15.7\%); mean age, $12.01 \pm 2.99$ years. The defect size $(p=0.002)$ and fracture type ( $p=0.017)$ were identified as the variables affecting the enophthalmometric difference between the eyes of non-operated patients. In the linear regression analysis, the variable affecting the fracture size was open-door type fracture $(p<0.001)$. Pearson's correlation analysis demonstrated a positive correlation between the enophthalmometric difference and the bony defect size $(p=0.003)$. Using receiver operating characteristic curve analysis, a cutoff value of $1.81 \mathrm{~cm}^{2}$ was obtained (sensitivity, 0.543; specificity, $0.724 ; p=0.002$ ).

Conclusion: The incidence of enophthalmos in pediatric pure orbital fractures was found to increase with fracture size, with an even higher incidence when open-door type fracture was a cofactor. In clinical settings, pediatric orbital fractures larger than $1.81 \mathrm{~cm}^{2}$ may be considered as extensive fractures that can result in enophthalmos and consequent cosmetic problems.
\end{abstract}

Keywords: Enophthalmos / Orbital fractures / Pediatrics

\section{INTRODUCTION}

Facial bone fractures are relatively uncommon in children compared with adults. This is known to be due to anatomical factors, such as skeletal flexibility and reduced sinus pneumatiza-

\section{Correspondence: Jae Ha Hwang}

Department of Plastic and Reconstructive Surgery, Chonnam National University

Medical School, 42 Jebong-ro, Dong-gu, Gwangju 61469, Korea

E-mail: psjhhwang@daum.net

Received August 6, 2020 / Revised September 2, 2020 / Accepted October 12, 2020 tion. The most common pediatric facial bone fractures are orbital fractures, which account for $29.8 \%$ of all cases [1].

Orbital growth in children is completed by $6-8$ years of age, while growth and aeration of the maxillary sinuses reach their full size by the age of 16 when dentition is completed. In the pediatric population, medial and floor fractures are more common than roof orbital fractures, as are fractures with mild displacement limited by the bony elasticity, orbital periosteum, supporting ligaments, and rapid recoil. Consequently, enoph- 
thalmos or vertical orbital dystopia are not as common as in adults; thus, nonoperative treatment is recommended [1-4].

In adults, indications for surgical treatment of orbital fractures are: radiographic evidence of an extensive fracture that can result in muscle incarceration, causing double vision, enophthalmos, or exophthalmos; orbital volume change; and visual acuity deficit or blow-in fracture caused by a presumed invasion of the optical canal by the fracture that does not react to steroids. The criteria for extensive pure orbital fractures are a fracture size of over $2 \mathrm{~cm}^{2}$ or a bony defect greater than $50 \%$ [5-10].

Contrarily, the majority of pediatric orbital fractures are treated conservatively. Albeit rarely, these fractures can result in enophthalmos when extensive. Furthermore, parents or guardians often refuse surgical treatment due to concerns regarding general anesthesia despite the potential for enophthalmos. Therefore, there is a need for clearly established criteria for pediatric extensive orbital fractures so that parents or guardians can be timely warned and treatment plans established $[2,3]$.

In line with the saying "Children are not small adults." pediatric patients often present with fractures that are difficult to diagnose, such as white-eyed blowout fractures, or fracture patterns that are different from those in adults. Thus, applying the same thresholds for enophthalmos in children as in adults is inappropriate, as the orbital volume and bone size in children are different from those in adults. Hence, in this study, we aimed to establish criteria for extensive fractures that may result in enophthalmos and to define the surgical indications for pediatric orbital fractures based on the enophthalmos severity, the fracture pattern, and size at the time of injury obtained from pediatric patients with orbital fractures who had not undergone surgical treatment.

\section{METHODS}

\section{Study design and patients}

We retrospectively reviewed the medical records and computed tomography (CT) images of patients aged $0-15$ years who were diagnosed with an orbital fracture in our hospital from January 2010 to February 2019. According to the exclusion criteria, patients with impure orbital fractures involving other facial bones, orbital roof or lateral wall fractures, or bilateral orbital fractures, and those who did not undergo a follow-up for over 6 months were excluded from the study.

The following data were collected from the medical records: age, sex, mechanism of trauma, location of fracture, presence of orbital symptoms at the time of injury, provision of surgery, and Hertel exophthalmometry results at the final follow-up after at least 6 months. CT image analysis was performed to collect data on the fracture type and bony defect size. The mechanism of trauma was categorized as follows: assault, fall, slip, sports injury, or traffic accident. Fractures were classified based on the location (left or right, further categorized as medial wall, inferior wall, or both medial and inferior wall fractures) and the fracture type (linear, trapdoor, or open-door fractures).

Based on whether they had undergone surgical treatment, patients were divided into two groups: operated and non-operated. Data were analyzed and compared between the groups.

\section{CT image analysis}

Facial or orbital CT images taken at the time of injury were used to determine the type of fracture and the size of the bony defect of the orbital wall using INFINITT PACS M6 software (INFINITT Healthcare Co., Ltd., Seoul, Korea).

Fractures with mild displacement, such as linear and greenstick fractures, were defined as linear-type fractures. Fractures with remarkable bone chip displacement and herniation of soft tissue from the orbit, such as comminuted or severe fractures, were defined as open-door-type fractures. Fractures with muscle or soft tissue entrapment in the absence of severe bony displacement or in the presence of small defects in the form of a door hinge were defined as trapdoor-type fractures (Fig. 1).

The size of the orbital wall defect was measured using threedimensional (3D) CT, where possible. In cases where 3D CT measurements were not taken or were not possible, the diameter of the section with the largest two-dimensional defect size was measured (Fig. 2). Subsequently, the defect size was calculated by multiplying the measured diameters, assuming the defect to be rectangular in shape.

\section{Statistical analysis}

Data were analyzed using IBM SPSS Statistics version 26 (IBM Corp., Armonk, NY, USA). Statistical significance was set at $p<0.05$.

To compare the differences between groups in each variable, Student $t$-test was performed for continuous variables and a chi-square test was performed for categorical variables. If Levene's test demonstrated a heterogeneity of variance in the distribution of dependent variables, Welch $t$-test was applied to the results. Logistic regression analysis was used to identify the variables that affected the occurrence of orbital symptoms, and linear regression analysis was used to identify the variables that affected the bony defect size. Pearson's correlation analysis was conducted to investigate the correlation of the enophthalmometric difference between the eyes of non-operated patients with the bony defect size. Receiver operating characteristic (ROC) curve analysis was performed and the area under the curve 

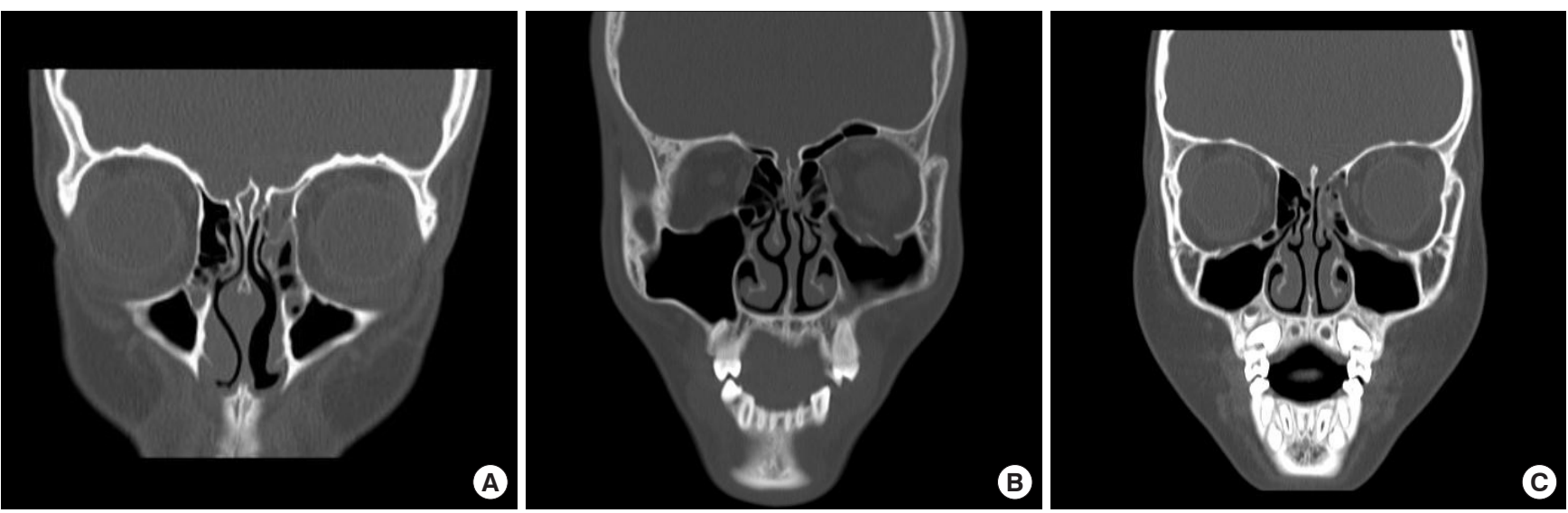

Fig. 1. Types of fractures. (A) Linear-type fracture in the left medial orbital wall. (B) Open-door-type fracture in the left inferior orbital wall. The orbital fat is herniated through the fractured orbital wall. (C) Trapdoor-type fracture in the left medial orbital wall. The orbital soft tissue is entrapped by the fracture fragments.
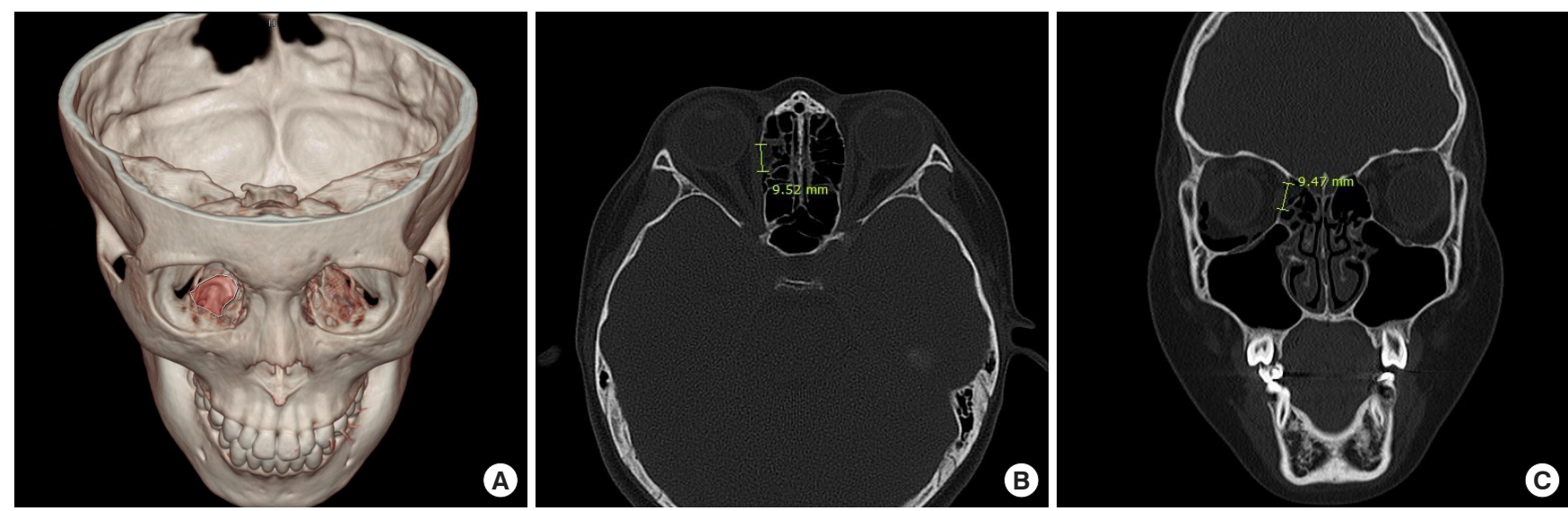

Fig. 2. Method of bony defect measurement. (A) Right inferior orbital bony defect measured with three-dimensional facial computed tomography. (B, C) Right medial orbital bony defect measured with two-dimensional sections.

(AUC) was calculated to define the point of maximum sensitivity and specificity as the cutoff value.

\section{RESULTS}

According to the inclusion and exclusion criteria, 305 pediatric patients diagnosed with pure orbital fractures from January 2010 to February 2019 were included in the study.

The patients' and the characteristics of the fractures are presented in Table 1. There were 257 males (84.3\%) and 48 females $(15.7 \%)$ with a mean age at the time of injury of $12.01 \pm 2.99$ years. In terms of fracture location, more than half involved the left eye (58.0\%), with equal involvement of the inferior and medial walls (40.0\% each). Regarding the fracture type, opendoor-type fractures were the most common ( $n=113,37.0 \%)$, followed by trapdoor-type $(n=94,30.8 \%)$ and linear-type fractures $(n=64,21.0 \%)$. The average bony defect size was $1.58 \pm$
$1.40 \mathrm{~cm}^{2}$. The most common mechanisms of trauma were assault ( $\mathrm{n}=96,31.5 \%)$ and slip $(\mathrm{n}=90,29.5 \%)$ (Table 1). Among all the patients, $85(27.9 \%)$ were surgically treated and 220 (72.1\%) did not undergo surgery. The average age of non-operated patients was $11.95 \pm 3.04$ years. The difference in Hertel exophthalmometry results at final follow-up between both orbits in non-operated patients was $0.32 \pm 0.65 \mathrm{~mm}$ (range, $0-2.5$ $\mathrm{mm}$ ), and the mean value of the difference was $1.39 \pm 0.60 \mathrm{~mm}$. In particular, 15 patients had an enophthalmometric difference of $2 \mathrm{~mm}$ or more.

On comparing Hertel exophthalmometric differences in the non-operated group, there was a significant difference in the bony defect size, which was significantly greater in the presence of an enophthalmometric difference $\left(1.78 \pm 1.17 \mathrm{~cm}^{2}\right.$ vs. $1.20 \pm$ $\left.1.15 \mathrm{~cm}^{2} ; p=0.002\right)$. There was also a significant difference in the fracture type $(p=0.017)$; when an enophthalmometric difference was present, open-door-type fractures were most com- 
Table 1. Characteristics of pediatric pure orbital fractures in all patients

\begin{tabular}{|c|c|}
\hline Variable & Value $(n=305)$ \\
\hline Age (yr) & $12.01 \pm 2.99$ \\
\hline Defect size $\left(\mathrm{cm}^{2}\right)$ & $1.58 \pm 1.40$ \\
\hline \multicolumn{2}{|l|}{ Sex } \\
\hline Male & $257(84.3)$ \\
\hline Female & $48(15.7)$ \\
\hline \multicolumn{2}{|l|}{ Location of fracture } \\
\hline Inferior wall & $122(40.0)$ \\
\hline Medial wall & $122(40.0)$ \\
\hline Both & $61(20.0)$ \\
\hline \multicolumn{2}{|l|}{ Type of fracture } \\
\hline Linear (medial or inferior) & $64(21.0)$ \\
\hline Open-door (medial or inferior) & $113(37.0)$ \\
\hline Trapdoor (medial or inferior) & $94(30.8)$ \\
\hline Open-door (both) & $11(3.6)$ \\
\hline Trapdoor (both) & $13(4.3)$ \\
\hline Open/trapdoor (both) & $10(3.3)$ \\
\hline \multicolumn{2}{|l|}{ Injured eye } \\
\hline Left & $177(58.0)$ \\
\hline Right & $128(42.0)$ \\
\hline \multicolumn{2}{|l|}{ Surgical treatment } \\
\hline Yes & $85(27.9)$ \\
\hline No & $220(72.1)$ \\
\hline \multicolumn{2}{|l|}{ Orbital symptoms } \\
\hline Yes & $115(37.7)$ \\
\hline No & $189(62.3)$ \\
\hline \multicolumn{2}{|l|}{ Mechanism of trauma } \\
\hline Assault & $96(31.5)$ \\
\hline Fall & $17(5.6)$ \\
\hline Slip & $90(29.5)$ \\
\hline Sports injury & $55(18.0)$ \\
\hline Traffic accident & 47 (15.4) \\
\hline
\end{tabular}

Values are presented as mean $\pm \mathrm{SD}$ or number (\%).

mon (54.3\%), whereas when an enophthalmometric difference was absent, trapdoor-type (35.6\%) followed by linear-type fractures (27.6\%) were most common (Table 2).

In the linear regression analysis of variables affecting the bony defect size in non-operated patients, only the fracture type demonstrated a significant effect $(p<0.001)$. In particular, a significant positive effect was observed in fractures other than the linear-type, with a relatively large effect of $\beta=0.74$ observed in open-door-type fractures (Table 3).

In the logistic regression analysis of variables that affected the occurrence of orbital symptoms in all patients (Table 4), the mechanism of trauma and the fracture type demonstrated a significant effect. In particular, trauma from traffic accidents
Table 2. Patient and fracture characteristics based on the enophthalmometric difference in non-operated patients

\begin{tabular}{|c|c|c|c|c|}
\hline \multirow{2}{*}{ Variable } & \multicolumn{2}{|c|}{ Enophthalmometric difference } & \multirow{2}{*}{$\begin{array}{c}\text { Total } \\
(\mathrm{n}=220)\end{array}$} & \multirow{2}{*}{$p$-value } \\
\hline & Yes $(n=46)$ & No $(n=174)$ & & \\
\hline Age (yr) & $12.54 \pm 2.61$ & $11.80 \pm 3.14$ & $11.95 \pm 3.04$ & 0.140 \\
\hline Defect size $\left(\mathrm{cm}^{2}\right)$ & $1.78 \pm 1.17$ & $1.20 \pm 1.15$ & $1.32 \pm 1.18$ & 0.002 \\
\hline Location of fracture & & & & 0.800 \\
\hline Inferior wall & $15(32.6)$ & 66 (37.9) & $81(36.8)$ & \\
\hline Medial wall & $22(47.8)$ & $76(43.7)$ & $98(44.5)$ & \\
\hline Both & $9(19.6)$ & $32(18.4)$ & $41(18.6)$ & \\
\hline Type of fracture & & & & 0.017 \\
\hline $\begin{array}{l}\text { Linear } \\
\text { (medial or inferior) }\end{array}$ & $6(13.0)$ & $48(27.6)$ & $54(24.5)$ & \\
\hline $\begin{array}{l}\text { Open-door } \\
\text { (medial or inferior) }\end{array}$ & $25(54.3)$ & 49 (28.2) & $74(33.6)$ & \\
\hline $\begin{array}{l}\text { Trapdoor } \\
\text { (medial or inferior) }\end{array}$ & $10(21.7)$ & $62(35.6)$ & $72(32.7)$ & \\
\hline Open-door (both) & 0 & $2(1.1)$ & $2(0.9)$ & \\
\hline Trapdoor (both) & $3(6.5)$ & $8(4.6)$ & $11(5.0)$ & \\
\hline Open/trapdoor (both) & $2(4.3)$ & $5(2.9)$ & $7(3.2)$ & \\
\hline
\end{tabular}

Values are presented as mean $\pm \mathrm{SD}$ or number (\%).

${ }^{a}$ Chi-square test or Student $t$-test.

Table 3. Linear regression analysis between defect size and predictors in non-operated patients

\begin{tabular}{lccc}
\hline Predictor & SE & $\beta$ & $p$-value \\
\hline Age & 0.02 & 0.05 & 0.217 \\
Mechanism of trauma & & & \\
Assault & - & - & (Reference) \\
Fall & 0.24 & -0.01 & 0.861 \\
Slip & 0.12 & 0.01 & 0.748 \\
Sports injury & 0.14 & 0.00 & 0.949 \\
Traffic accident & 0.16 & 0.02 & 0.647 \\
Location of fracture & & & \\
Inferior wall & 0.18 & -0.08 & 0.182 \\
Medial wall & 0.18 & 0.06 & 0.367 \\
Both & - & - & (Reference) \\
Type of fracture & & & \\
Linear (medial or inferior) & - & - & $($ Reference) \\
Open-door (medial or inferior) & 0.14 & 0.74 & $<0.001$ \\
Trapdoor (medial or inferior) & 0.14 & 0.33 & $<0.001$ \\
Open-door (both) & 0.31 & 0.63 & $<0.001$ \\
Trapdoor (both) & 0.30 & 0.34 & $<0.001$ \\
Open/trapdoor (both) & 0.32 & 0.39 & $<0.001$ \\
\hline
\end{tabular}

SE, standard error; $\beta$, correlation coefficient.

a)Linear regression analysis.

was 2.343 times more likely to cause orbital symptoms than trauma from assault ( $p=0.045$ ). Open-door-type fractures were 2.901 times more likely to cause orbital symptoms than lineartype fractures, with a 14.469 times greater chance when involv- 
Table 4. Logistic regression analysis between orbital symptoms and predictors in all patients

\begin{tabular}{|c|c|c|}
\hline Predictor & OR $(95 \% \mathrm{Cl})$ & $p$-value $e^{a)}$ \\
\hline Age & 1.080 (0.979-1.192) & 0.123 \\
\hline \multicolumn{3}{|l|}{ Mechanism of trauma } \\
\hline Assault & 1 & (Reference) \\
\hline Fall & $1.181(0.335-4.162)$ & 0.795 \\
\hline Slip & $1.394(0.734-2.651)$ & 0.310 \\
\hline Sports injury & $0.827(0.388-1.764)$ & 0.624 \\
\hline Traffic accident & $2.343(1.019-5.386)$ & 0.045 \\
\hline \multicolumn{3}{|l|}{ Location of fracture } \\
\hline Inferior wall & $1.656(0.671-4.086)$ & 0.273 \\
\hline Medial wall & $0.460(0.183-1.157)$ & 0.099 \\
\hline Both & 1 & (Reference) \\
\hline \multicolumn{3}{|l|}{ Type of fracture } \\
\hline Linear (medial or inferior) & 1 & (Reference) \\
\hline Open-door (medial or inferior) & $2.901(1.378-6.107)$ & 0.005 \\
\hline Trapdoor (medial or inferior) & $1.755(0.840-3.667)$ & 0.135 \\
\hline Open-door (both) & 14.469 (2.282-91.732) & 0.005 \\
\hline Trapdoor (both) & $1.918(0.416-8.848)$ & 0.404 \\
\hline Open/trapdoor (both) & $3.490(0.690-17.643)$ & 0.131 \\
\hline
\end{tabular}

$\mathrm{OR}$, odds ratio; $\mathrm{Cl}$, confidence interval.

a)Logistic regression analysis.

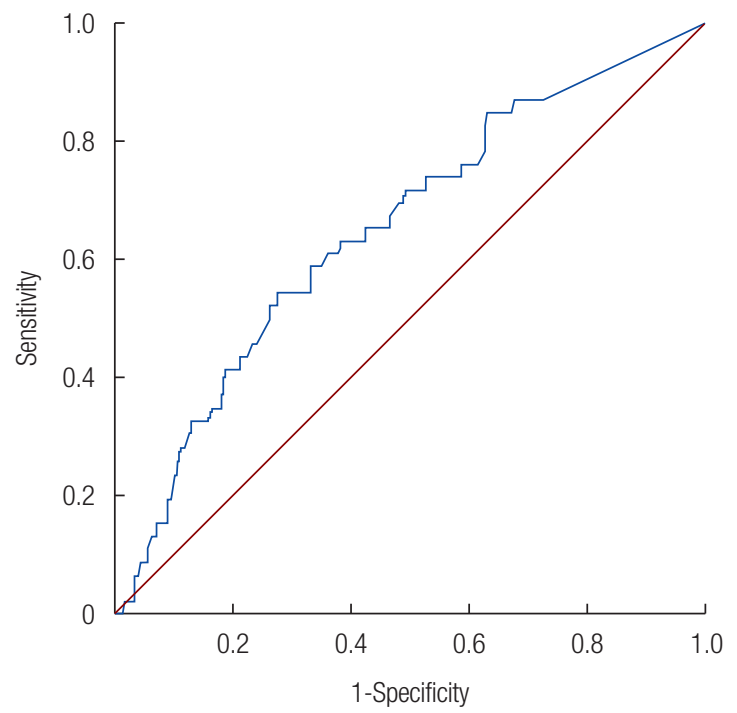

Fig. 3. Receiver operating characteristic curve of the enophthalmometric difference and the bony defect size in non-operated patients. The area under the curve was found to be significant at 0.649 ( $p=$ $0.002)$. The cutoff value, defined as the point of maximum sensitivity $(0.543)$ and specificity $(0.724)$, was $1.81 \mathrm{~cm}^{2}$.

ing both the medial and inferior orbital walls ( $p=0.005$ both).

Pearson's correlation analysis revealed a positive correlation between the enophthalmometric difference and the bony defect size in non-operated patients $(r=0.20 ; p=0.003)$. In the ROC curve analysis, the AUC was 0.649 , indicating significance $(p=0.002)$.
Table 5. Correlation between provision of surgical treatment and bony defect size in all patients

\begin{tabular}{lcccc}
\hline & \multicolumn{2}{c}{ Surgical treatment } & \multirow{2}{*}{$\begin{array}{c}\text { Total } \\
(n=305)\end{array}$} & $p$-value ${ }^{\text {a) }}$ \\
\cline { 2 - 3 } & Yes $(\mathrm{n}=85)$ & No $(\mathrm{n}=220)$ & & \\
\hline Defect size $\left(\mathrm{cm}^{2}\right)$ & $2.24 \pm 1.71$ & $1.32 \pm 1.18$ & $1.58 \pm 1.40$ & $<0.001$ \\
\hline
\end{tabular}

Values are presented as mean $\pm \mathrm{SD}$.

a) Welch $t$-test.

A cutoff value of $1.81 \mathrm{~cm}^{2}$ was established at the point of maximum sensitivity and specificity (Fig. 3).

Additionally, we also examined the correlation between the provision of surgical treatment and the bony defect size (Table 5). The mean bony defect size was significantly greater in patients in the operated group than in non-operated patients $(2.24 \pm 1.71$ $\mathrm{cm}^{2}$ vs. $\left.1.32 \pm 1.18 \mathrm{~cm}^{2} ; p<0.001\right)$.

\section{DISCUSSION}

In this study, we compared the enophthalmos severity and the fracture pattern and size at the time of injury in pediatric patients with pure orbital fractures based on the provision for surgical treatment in order to establish criteria for extensive fractures that can aid in defining surgical indications in this population. We found that the incidence of enophthalmos increased with the fracture size, particularly in open-door-type fractures. We determined that pediatric orbital fractures larger than $1.81 \mathrm{~cm}^{2}$ may be considered as extensive fractures that can result in enophthalmos and consequent cosmetic problems.

Pediatric orbital fractures tend to have characteristics of linear or trapdoor fractures due to bone flexibility. Additionally, the tendency for early recoil in children reduces the incidence of globe malposition, such as enophthalmos or vertical orbital dystopia [1]. Thus, conservative treatment is often performed in this population, unless entrapment or acute globe malposition are observed, which require immediate surgery. Furthermore, surgery may be deemed controversial due to concerns of growth disturbances due to the soft tissue stripping and fixation during surgery $[1,2]$. Nonetheless, the available evidence supports the need for surgical indications in children due to the potential of large fractures to cause changes in the orbital volume and enophthalmos [11], although it is questionable whether applying the same criteria as in adults is reasonable.

Although pediatric orbital growth is completed by $6-8$ years of age and there is a low incidence of orbital fractures in younger age groups, the incidence increases with increased aeration in the sinuses. As the midface reaches full size by the age of 16 , when dentition is completed, children up to 15 years of age were identified as pediatric patients for data collection in this study. 
The demographic data analysis indicated similar findings as those of previous studies [1,2]; orbital fractures were more common in male children, $56.1 \%$ were linear- or trapdoor-type fractures, with a $27.9 \%$ rate of surgical repair. However, based on the fact that the most common mechanisms of trauma in this study were assault, slip, and sports injury, in contrast to traffic accident and sports injury in previous studies [12], it can be presumed that the factors resulting in trauma were limited to those of weaker strength due to the exclusion of fractures other than pure orbital fractures in this study.

The fracture type and size were determined using facial CT images obtained at the time of injury and fracture-induced enophthalmos was examined through Hertel exophthalmometry measurements in non-operated patients during the follow-up. Generally, in adults, an enophthalmometric difference greater than $2 \mathrm{~mm}$ is known to carry a potential for cosmetic problems [13]. Although the patients in our study would still be children or adolescents after the follow-up, the enophthalmometric difference as an indicator of enophthalmos was set at $2 \mathrm{~mm}$, considering that orbital growth is completed by $6-8$ years of age. Based on this criterion, the mean fracture size was determined to be $1.78 \pm 1.17 \mathrm{~cm}^{2}$ and $1.20 \pm 1.15 \mathrm{~cm}^{2}$ in patients with and those without enophthalmos, respectively, indirectly supporting the hypothesis that a greater fracture size increases the incidence of enophthalmos. Thus, we aimed to determine the fracture size at which enophthalmos would occur. We further found that open-door-type fractures were dominant in patients with enophthalmos, whereas trapdoor-type or linear-type fractures were dominant in those without enophthalmos, which is in line with previously reported findings [11], suggesting that opendoor-type fractures caused remarkable orbital volume changes.

In the analysis aimed to identify factors affecting the fracture size, open-door-type fractures demonstrated a dominant effect, which is consistent with their definition, inclusive of burst out orbital tissue and comminuted fractures. None of the remaining variables (age, trauma mechanism, or fracture location) showed an effect. In the analysis aimed to identify factors affecting the occurrence of orbital symptoms, it was observed that the severity of symptoms was greater when the fracture mechanism was a traffic accident, which may be attributed to the stronger force inflicted by these type of injuries, as mentioned previously. A similar explanation can be applied for the higher incidence of symptoms in open-door-type fractures. Moreover, one can deduce that orbital symptoms in open-doortype fractures may be caused by changes in the orbital volume, which in turn may cause globe malposition, such as enophthalmos or vertical orbital dystopia.

In this study, a direct, positive correlation was identified be- tween the enophthalmometric difference and the fracture size, and the value of $1.81 \mathrm{~cm}^{2}$ was determined as the cutoff to predict the occurrence of enophthalmos with a sensitivity of 0.543 and a specificity of 0.724 . Although this value does not significantly differ from the criterion of $2 \mathrm{~cm}^{2}$ in adults, and considering that previous studies $[6,10,13]$ have reported that defects sized up to $2.3-2.6 \mathrm{~cm}^{2}$ should not cause cosmetic problems, it can be established as a sufficient criterion for the pediatric population. Given that the average age of the non-operated patients was $11.95 \pm 3.04$ years, and that their midface would have developed similar to that of an adult, this may have introduced bias. Additionally, the analysis comparing the fracture size between the operated and non-operated patients indicated that the bony defect size was larger among the former by approximately $1 \mathrm{~cm}^{2}$. Furthermore, of the 85 patients who underwent surgery, 22 and 18 patients had muscle entrapment and entrapment of soft tissue including fat tissue, respectively; other patients underwent surgery for globe malposition following orbital volume changes due to soft tissue herniation, induced by a blowout fracture or orbital symptoms such as visual impairment. This may be attributed to the fact that patients with acute globe malposition or orbital symptoms opted for urgent operation or elective surgical repair, which demonstrates the need for clear indications for fracture size-related surgery in treatment planning.

The limitation of this study is the age range of the study subjects, which corresponds to a period when the eye development is complete and the midface is similar to that of adults. There were challenges in subject selection, as there is a low incidence of orbital fractures among children in the lower age range, which would reduce the number of recruited subjects, while those in the higher age range had completed development, presenting with characteristics similar to those of adults. Prospective studies with a long-term follow-up and data collection in a pediatric population with a lower age range may be more effective in establishing effective indications.

In conclusion, we demonstrated that the incidence of enophthalmos in pediatric pure orbital fractures increased with the fracture size, becoming even higher with open-type fractures as a cofactor. In pediatric patients with pure orbital fractures larger than $1.81 \mathrm{~cm}^{2}$, surgical repair may be recommended, as such fractures may later result enophthalmos with an enophthalmometric difference of $2 \mathrm{~mm}$ or more and consequent cosmetic problems. Based on the findings of the present and those of previous studies $[1,6,9,14,15]$, the surgical indications for pediatric orbital fractures are as follows: symptoms due to incarceration of muscle or soft tissue, such as diplopia; orbital symptoms requiring decompression, such as visual acuity deficit; acute 
globe malposition due to orbital volume change, such as enophthalmos or vertical orbital dystopia; and extensive fractures with a defect size greater than $1.81 \mathrm{~cm}^{2}$ according to CT findings, which may result in enophthalmos.

\section{NOTES}

\section{Conflict of interest}

No potential conflict of interest relevant to this article was reported.

\section{Ethical approval}

The study was approved by the Institutional Review Board of Chonnam National University Hospital (IRB No. CNUH-2020216) and performed in accordance with the principles of the Declaration of Helsinki.

\section{Patient consent}

The patient's guardian provided written informed consent for the publication and the use of patient images.

\section{ORCID}

$\begin{array}{ll}\text { Seung Hyun Kim } & \text { https://orcid.org/0000-0001-8269-2036 } \\ \text { Jun Ho Choi } & \text { https://orcid.org/0000-0002-4848-517X } \\ \text { Jae Ha Hwang } & \text { https://orcid.org/0000-0001-6992-8067 } \\ \text { Kwang Seog Kim } & \text { https://orcid.org/0000-0002-6766-4640 } \\ \text { Sam Yong Lee } & \text { https://orcid.org/0000-0002-3185-2519 }\end{array}$

\section{REFERENCES}

1. Davidson EH, Losee JE. Pediatric facial fractures. In: Neligan PC, Rodriguez ED, Losee JE, editors. Plastic surgery: craniofacial, head and neck surgery and pediatric plastic surgery. Vol 3. 4th ed. London: Saunders Elsevier; 2018. p. 678-95.

2. Hink EM, Durairaj VD. Evaluation and treatment of pediatric orbital fractures. Int Ophthalmol Clin 2013;53:103-15.

3. Oppenheimer AJ, Monson LA, Buchman SR. Pediatric orbital fractures. Craniomaxillofac Trauma Reconstr 2013;6:9-20.

4. Lee HR, Jung GY, Lee DL, Shin HK. Pediatric orbital medial wall trapdoor fracture with normal computed tomography findings. Arch Craniofac Surg 2017;18:128-31.

5. Rodriguez ED, Dorafshar AH, Manson PN. Facial injuries. In: Neligan PC, Rodriguez ED, Losee JE, editors. Plastic surgery: craniofacial, head and neck surgery and pediatric plastic surgery. Vol 3. 4th ed. London: Saunders Elsevier; 2018. p. 47-81.

6. Kang DH. Orbital wall restoring surgery with primary orbital wall fragments in blowout fracture. Arch Craniofac Surg 2019; 20:347-53.

7. Choi SH, Kang DH, Gu JH. The correlation between the orbital volume ratio and enophthalmos in unoperated blowout fractures. Arch Plast Surg 2016;43:518-22.

8. Senese O, Boutremans E, Gossiaux C, Loeb I, Dequanter D. Retrospective analysis of 79 patients with orbital floor fracture: outcomes and patient-reported satisfaction. Arch Craniofac Surg 2018;19:108-13.

9. Kim HS, Jeong EC. Orbital floor fracture. Arch Craniofac Surg 2016;17:111-8.

10. Lee HB, Lee SH. New anthropometric data for preoperative planning in orbital wall fracture treatment: the use of eyelid drooping. Arch Craniofac Surg 2018;19:248-53.

11. Losee JE, Afifi A, Jiang S, Smith D, Chao MT, Vecchione L, et al. Pediatric orbital fractures: classification, management, and early follow-up. Plast Reconstr Surg 2008;122:886-97.

12. Takahashi Y, Nakakura S, Sabundayo MS, Kitaguchi Y, Miyazaki $\mathrm{H}$, Mito $\mathrm{H}$, et al. Differences in common orbital blowout fracture sites by age. Plast Reconstr Surg 2018;141:893e901e.

13. Kim YJ, Kim JR, Yang JW. Functional outcomes compared between conservative treatment and surgical treatment of orbital wall fractures: a retrospective study. Ann Optom Contact Lens 2015;14:7-16.

14. Hink EM, Wei LA, Durairaj VD. Clinical features and treatment of pediatric orbit fractures. Ophthalmic Plast Reconstr Surg 2014;30:124-31.

15. Yoo YJ, Yang HK, Kim N, Hwang JM. Pediatric orbital wall fractures: prognostic factors of diplopia and ocular motility limitation. PLoS One 2017;12:e0184945. 